\title{
Intercavernous portion of internal carotid artery occlusion resulting from snowboarding
}

This article was published in the following Dove Press journal:

International Medical Case Reports Journal

6 April 2010

Number of times this article has been viewed

\author{
Sudiptamohan Mukhopadhyay' \\ Awen lorwerth ${ }^{2}$ \\ 'Department of Orthopaedics, \\ University Hospital of Wales, \\ Cardiff, UK; ${ }^{2}$ Department \\ of Orthopaedics, Royal Glamorgan \\ Hospital, Wales, UK
}

\begin{abstract}
A 33-year-old gentleman who was otherwise fit and healthy suffered repetitive low impact head injuries while snowboarding in Austria over a period of one week. During the fall he had several hyperextension injuries and presented with headache, nausea, vomiting, drowsiness (felt 'drunk' on Friday night despite not being drunk), diplopia, abnormal pupillary signs. A Horner's syndrome was diagnosed and on investigation, the left intercavernous portion of internal carotid artery (ICA) was found to be thrombosed. The symptoms gradually settled after conservative treatment for a month. Blunt head trauma is a recognized cause of carotid dissection and thrombosis and many neuromechanics studies have attempted to calculate the wall shear stress involved. Physicians treating snowboarders should be aware of the condition and should look for Horner's syndrome and consider the possibility of carotid occlusion. With a thorough PubMed, Ovid, EMBASE search using ‘snowboarding', 'carotid dissection', 'Horner's syndrome' no such case was found to be reported. Proper training for such sport activities is essential to avoid serious consequences.
\end{abstract}

Keywords: snowboarding, carotid dissection, Horner's syndrome

\section{Introduction}

Blunt cerebrovascular injuries (BCVI) resulting in carotid dissection has been described in the literature following various sports activities. Snowboarding as a cause of similar injury resulting in occulosympathetic paresis has not yet been published. The aim of this case report is to emphasize the need for proper training prior to such sport activities and also to highlight a remarkable outcome with complete resolution of carotid artery thrombosis over time.

\section{Case report}

A 33-year-old gentleman who was otherwise fit and healthy was snowboarding in Austria. He fell backwards on fairly soft snow several times during the week. After his worst fall, again on soft snow, he felt 'drunk' despite not being intoxicated. At no time did he lose consciousness, have a headache, drowsiness, nausea, or vomiting. He entered a dark chalet for lunch and realized his left eye was unable to adapt to light and dark. The following day, just before flying home, his wife noticed a difference in pupil size. He presented to our hospital straight after returning to the UK. The only positive finding during examination was a difference in pupillary size $(3 \mathrm{~mm}$ left as opposed to $5 \mathrm{~mm}$ right). The pupils reacted normally to accommodation but not to light. On application of $1 \%$ tropicamide and $2.5 \%$ phenylephrine, both pupils dilated equally and quickly. There were no photopsia/floaters, visual field loss/diplopia/blurred
Correspondence: Sudiptamohan Mukhopadhyay

Department of Orthopaedics, University Hospital of Wales, Cardiff, UK CFI4 4XW Tel +447828652404

Email sudiptomohan@rediffmail.com 
vision/eye pain/conjunctival injection. No hydrosis, or cranial nerve deficit was identified. Cervical spine examination was normal and fundi, disc, macula, and retina were normal. A clinical diagnosis of Horner's syndrome was made and investigations were carried out to exclude a probable cause of carotid dissection.

An initial computed tomography (CT) angiogram (Figure 1) showed no contrast filling the left internal carotid artery at the base of skull, and the artery was slightly enlarged in keeping with a thrombus. The intrapetrous and intracavernous portions did not enhance, with a trace of retrograde flow in the supraclinoid carotid artery. The circle of Willis was patent and the anterior, middle, and posterior cerebral arteries enhanced normally. The left vertebral artery was ectatic and patent, the right vertebral artery was not demonstrated. The patient was recalled to ultrasound his neck in order to delineate the lower end of the left carotid thrombosis/dissection.

A colour duplex carotids showed normal flow in the right common, internal, and external carotid arteries (CCA, ICA, ECA). Flow in the right vertebral artery was in a normal direction. On the left side there was an ill-defined intimal flap seen at the carotid bifurcation extending into the left ICA. Normal flow noted in the left CCA and ECA, but markedly damped flow in the proximal left ICA. The ICA could only be traced up the neck for a distance of approximately $3 \mathrm{~cm}$ from the bifurcation. Flow in the left vertebral artery is in a normal direction (left vertebral artery dominant). The conclusion was of a left ICA intimal dissection (Figure 2).

\section{Discussion}

Arterial dissection consists of intimal disruption, with extravasations of blood into layers of the arterial wall producing luminal stenosis, occlusion or aneurysm formation. ${ }^{1}$ Various causes of BCVI have been implicated in the causation of carotid dissection. $^{2-4}$

As the hematoma dissects into vessel wall it creates a false lumen (suboptimal dissection) or the adventitia (subadventitial dissection). It may rupture back into the arterial lumen, creating a double lumen or a re-entry phenomenon. Usually ICA dissections occur distal to the carotid bifurcation near the $\mathrm{C} 2$ level (beyond carotid Doppler range) and features of distal stenosis can be picked up from the Doppler signal. As in this case finding an intimal flap is not very uncommon.

Though wall shear stress from BCVI has been implicated in initiation of intimal tear in carotid dissection but recent studies fail to link such an association. ${ }^{5}$ Further studies have suggested that there may be individual propensity to develop arterial thrombosis. ${ }^{6}$

Oculosympathetic paresis is the third most common clinical presentation in patients with spontaneous dissection which may occur minutes to days after the onset of headache. ${ }^{7}$ It includes incomplete Horner's syndrome where facial sweating is unaffected. It appears to involve the post ganglionic sympathetic fibres running along the ICA with sparing of the external carotid plexus that produces sweating.

It is believed that occulosympathetic paresis resolves less frequently. It persists in two-thirds of patients due to permanent damage to sympathetic fibers in the internal carotid plexus. Clinical Horner's syndrome does not usually cause functional problems. Headache recovers in $95 \%$ of patients within three months; in this case it resolved by the fifth day. Although recanalization of a completely occluded vessel can occur, this is uncommon. Recurrence of dissection

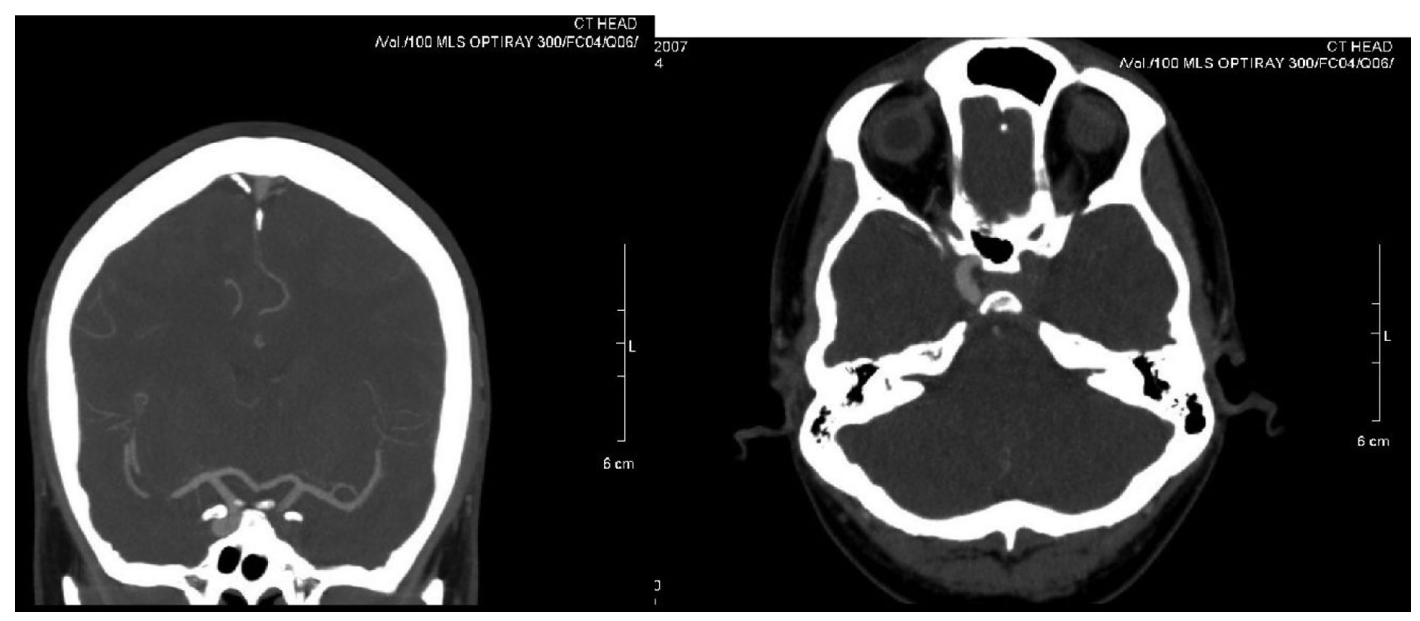

Figure I CT angiogram of blocked ICA.

Abbreviations: CT, computed tomography; ICA, internal carotid artery. 

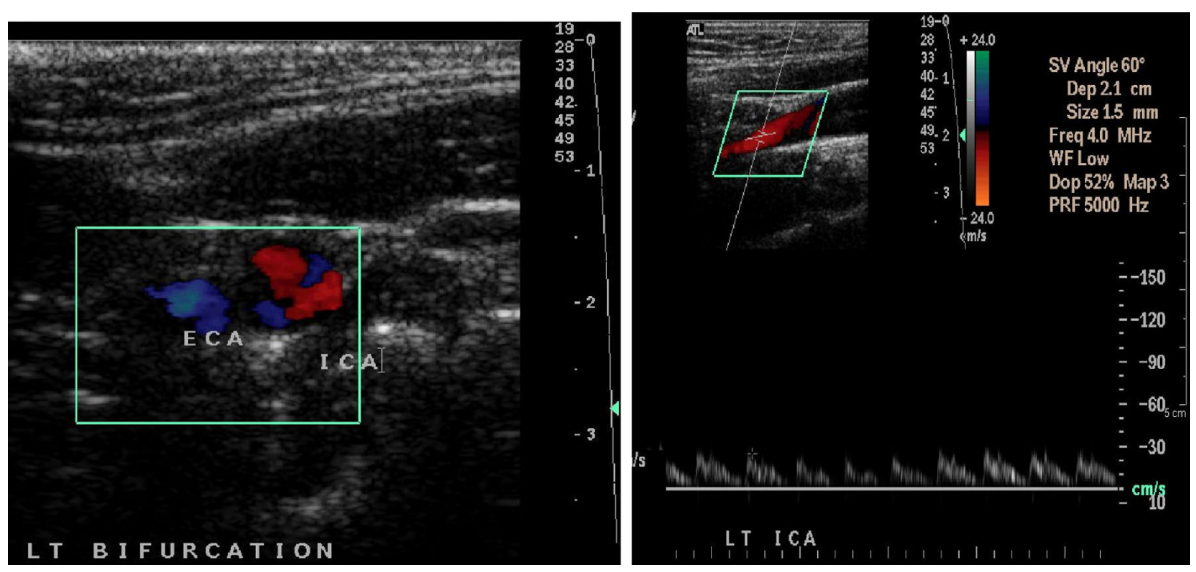

Figure 2 Doppler imaging of carotid artery dissection.

in the same vessel is extremely rare. ${ }^{8}$ Our patient experienced complete recovery from the Horner's syndrome.

More common symptoms include pain, unilateral headache, neck pain, scalp tenderness. Our patient though had headache, nausea, vomiting, drowsiness, and diplopia but didn't have any cerebral ischemic symptoms despite the intrapetrous and intracavernous portions of his ICA were completely occluded. There is increased incidence of intracranial aneurysms in patients with carotid artery dissections and familial associations have also been reported. Our patient didn't show any evidence of intracranial aneurysm.

According to the natural history of carotid dissection, $78 \%-92 \%$ of patients recover when they present with milder signs or symptoms. Those with fixed neurological deficit, which is common after traumatic dissection, do less well, with $40 \%$ chance of good recovery. Our patient had complete resolution (Figure 3) of the ICA occlusion at the seven-month follow-up.

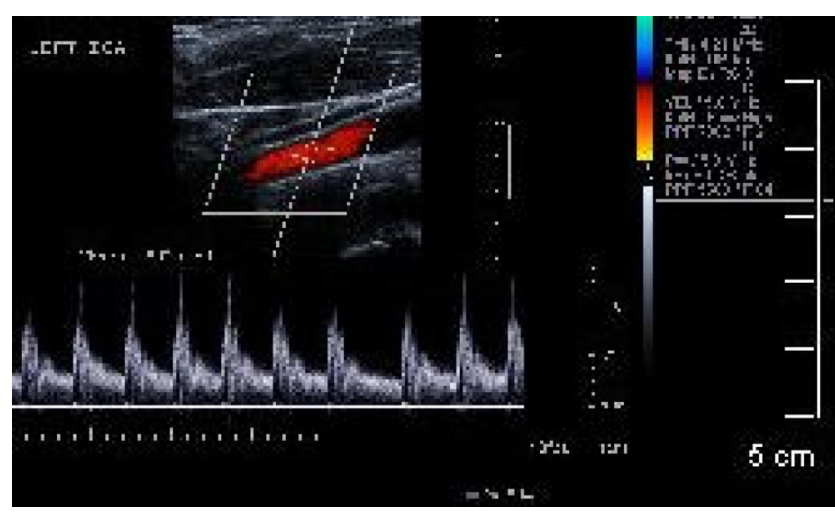

Figure 3 Doppler imaging of recanalization of ICA. Abbreviation: ICA, internal carotid artery.
Ehrenfield and Wylie ${ }^{9}$ originally advocated surgical management, but increasing evidence of unfavorable outcomes of surgical intervention, limited access, and technical difficulties obtaining distal control along with remarkable results of conservative treatment indicates treatment by anticoagulation.

\section{Conclusion}

BCVI are common in various contact sports and spontaneous carotid artery dissection as a consequence can present with subtle ocular symptoms. Conservative management with anticoagulation is the mainstay of therapy. Spontaneous resolution of symptoms is expected in most cases. Physicians treating snowboarders should be aware of the condition and should look for Horner's syndrome and consider the possibility of carotid occlusion. Proper training and appropriate equipment for such sport activities may help to avoid serious consequences. However, our case report cannot conclude that such training is essential.

\section{Disclosures}

This work was performed at the Department of Orthopedics, Royal Glamorgan Hospital, Wales, UK. The authors report no conflicts of interest in this work.

\section{References}

1. Mokri B. Dissection of cervical and cephalic arteries. In: Meyer FB, editor. Sundt's Occlusive Cerebrovascular Disease. Philadelphia, PA WB Saunders; 1994. p. 46.

2. Biffl WL, Ray CE Jr, Moore EE, et al. Treatment-related outcomes from blunt cerebrovascular injuries: importance of routine follow-up arteriography. Ann Surg. 2002;235(5):699-707.

3. Rutherford RB. Vascular Surgery. Fifth edition. Philadelphia, PA: WB Saunders; 2005. p. 1864.

4. Pierrot S, Bernardeschi D, Morrisseau-Durand MP, et al. Dissection of the internal carotid artery following trauma of the soft palate in children. Ann Otol Rhinol Laryngol. 2006;115:323-329. 
5. Kubis N, Checoury A, Tedgui A, Levy BI. Adaptive common carotid arteries remodelling after unilateral internal carotid artery occlusion in adult patients. Cardiovasc Res. 2001;50(3):597-602.

6. Wysokinski WE, McBane RD 2nd, Owen WG. Individual propensity for arterial thrombosis. Arterioscler Thromb Vasc Biol. 1999;19(4): 883-886.
7. Kerty E. The ophthalmology of internal carotid artery dissection. Acta Ophthalmol Scand. 1999;77(4):418-421.

8. Schievink WI, Roiter V. Epidemiology of cervical artery dissection. Front Neurol Neurosci. 2005;20:12-15.

9. Ehrenfield WR, Wylie EJ. Spontaneous dissection of the internal carotid artery. Arch Surg. 1976;111:1294.

\section{Publish your work in this journal}

The International Medical Case Reports Journal is an international, peer-reviewed open-access journal publishing original case reports from all medical specialties. Previously unpublished medical posters are also accepted relating to any area of clinical or preclinical science. Submissions should not normally exceed 2,000 words or
4 published pages including figures, diagrams and references. The manuscript management system is completely online and includes a very quick and fair peer-review system, which is all easy to use. Visit http://www.dovepress.com/testimonials.php to read real quotes from published authors.

Submit your manuscript here: http://www.dovepress.com/international-medical-case-reports-journal-journal 